\title{
Introducing low vision care into the Government eye care services in South Africa
}

\section{AO Oduntan*}

Department of Optometry, University of Limpopo, Turfloop Campus, P Bag x1106, Sovenga, 0727 South Africa

<alabio@ul.ac.za>

\begin{abstract}
There are many visually impaired people all over the world including South Africa, unfortunately, vision rehabilitation services are lacking in many countries. Currently in South Africa, low vision care is offered by a few private optometric practitioners, optometric institutions and non-governmental organizations. Although most of the major Government hospitals in the country provide ophthalmological services to patients, only a few of these provide optometric services and none provides low vision care services yet. There is therefore, a great need to increase vision rehabilitation services in the country. There are plans to introduce optometry sections into government hospitals in every Province of South Africa and these plans include introduction of low vision care as part of the optometric services. There is, therefore a need for information on how to introduce low vision care services into existing optometry facilities in the Government hospitals and those that may be established in the future. The purpose of the article is to discuss how low vision services can be introduced into public eye care facilities. Issues relating to rehabilitation of visually impaired patients, low vision care, infrastructure, equipment, low vision devices and human resources are discussed in this paper. To justify the facility needs, basic information on assessment procedure of low vision patients is included. Also, names and contact details of a few companies supplying low vision devices in South Africa are provided. The contents of this article will be useful to health care managers in the government hospitals; especially those in charge of the optometry services as well as the optometrists who may wish to work in the low vision care sections in Government hospitals.
\end{abstract}

Key Words: Vision rehabilitation, Blindness, Low vision care, Optometrists, Government hospitals in South Africa.

\section{Introduction}

\section{Optometry in the Public Sector}

Hospitals and comprehensive health care environments tend to orientate themselves to the communities that they serve in ways that single or even association practice of optometry cannot provide. They provide services for low income patients and special population groups such as the developmentally disabled ${ }^{1}$. Optometry has much to offer in the eye care services in the government hospitals as it is well positioned as a primary health care profession ${ }^{2}$. The essential value of optometric care in a hospital and in a medical centre or in a comprehensive health environment stems from the opportunity to lend optometry's unique talent and professional abilities to the other services that professional disciplines offer in a comprehensive environment, all for the benefit of the patient ${ }^{1}$. Also, it is an opportunity for learning from disciplines other than optometry, and for all healthcare professionals to understand the skills, talents and services that optometry provides. 
This interaction increases the understanding of what optometry can do to strengthen overall services to patients and how optometry can maximize the professional efforts of other disciplines for the benefits of the patients ${ }^{1}$. Optometry in the comprehensive health care systems such as government hospitals may also provide specialty services such as low vision care.

Traditionally, in South Africa, optometry has been practiced primarily as solo and less commonly as group practices. The situation has been changing within the past decade or so, as optometry is being introduced into the government health care systems in the country. Optometrists are now being employed to work in the government hospitals, where they currently do refraction and provide spectacle prescription, and in some cases dispense glasses to the patients. These services need to be expanded to include specialty areas such as low vision, contact lenses, binocular vision et cetera.

\section{Definitions, causes, prevalence and consequences}

Low vision has been defined in various ways by different authors as presented in previous articles ${ }^{3,4}$ in this journal. Also, different values of visual functions such as visual acuity (VA), visual field (VF), contrast sensitivity (CS) are used to describe the condition in different countries, by different organizations and individuals. In spite of these complexities in definition, low vision can simply be described as reduced visual functions such as visual acuity, visual field et cetera which cannot be ameliorated by medical, surgical or regular ophthalmic treatment. However, for the purpose of effective communication between eye care practitioners, researchers, government and non-governmental organizations, definitions quantifying the remaining visual functions are preferable. In this regard, the most commonly used definition of low vision is VA less than $6 / 18$, but equal or better than $3 / 60(6 / 120)$, or visual field loss to less than $20^{\circ}$ (degrees) in the better eye with best possible correction ${ }^{5}$. There are modifications of this definition ${ }^{6,7}$ as discussed in a recent article by Sacharowitz ${ }^{4}$.

Low vision can result from various ocular or systemic conditions or diseases which may be genetic or acquired. Those of genetic origin include albinism, congenital cataract, corneal dystrophies, retinitis pigmentosa et cetera. The acquired ones include cataract (traumatic or senile), maculopathies such as macula degeneration, diabetic retinopathy, hypertensive retinopathy, glaucoma, vitamin A deficiency, trauma and diseases such as measles, trachoma and onchocerciasis. The prevalence of low vision in Africa has been reported to be $3 \%{ }^{8}$. The prevalence varies from one country to another and even, within the same country; it may vary from one Province to another. Also, in the same community, the prevalence may vary with age. In South Africa, the prevalence of low vision has been estimated at $0.32 \%{ }^{9}$. A population based study in the Limpopo Province found prevalence of low vision to be $1.1 \%$ among adults aged 18 years and older ${ }^{3}$.

Due to reduced VA, low vision patients may experience difficulties in reading at near and far. With near reading problems, they may not be able to read print, including personal letters and print on the computer screen or letters or numerals on the computer keyboard. With reduced distance vision, they may experience difficulty recognizing faces, reading street names, seeing traffic signs and house numbers. They may experience difficulty traveling alone or driving due to poor vision. Those with visual field loss may also have serious problems with reading, mobility and driving, depending on the degree and type of field loss. Visual impairment can leave a person anxious, depressed, confused or even fearful of his or her surroundings ${ }^{10}$. Therefore, persons with visual impairment have to depend on family members or friends for many mundane activities. Low vision patients, like the blind ones are therefore, faced with functional difficulties which may result in social, economic and psychological problems. They therefore, need assistance in the form of vision rehabilitation. Although there is no possibility of reversing the visual impairment in low vision patients, people with the condition can return to an active, productive, rewarding and independent lifestyle with low vision devices and rehabilitation training ${ }^{10,11}$.

\section{Low vision care and visual rehabilitation}

Low vision care has been given little attention in different parts of the world, especially in the developing countries. Vision 2020, the Right to Sight, a World Health Organization (WHO) ${ }^{12}$ initiative has provided a new impetus to the concept of comprehensive eye care encompassing eye health promotion and prevention of blindness, treatment of eye diseases and rehabilitation services for people with incurable eye 
conditions ${ }^{13}$. The hitherto underdeveloped component of low vision, along with services for refractive errors, has been identified as a priority area for intervention ${ }^{12}$. In view of the Vision 2020 initiative, rehabilitation of low vision patients is now being given attention in different parts of the world including South Africa.

Rehabilitation in relation to health care has been defined as a process of helping handicapped individuals move from position of dependency towards a position of independence in a community of their choice ${ }^{14}$. For instance, a low vision patient who otherwise may not be able to move around independently may be able to do so after undergoing a visual examination; provision of a telescope and appropriate mobility training. A low vision patient who is not able to read personal mail may be able to do so following the provision of an appropriate magnifier and training of its use.

Rehabilitation strategies for patients with visual impairment have been considered to be functional, goal or attitude oriented ${ }^{10}$. The functional oriented strategy consists of providing the patient with assistive technology such as CCTV, teaching him or her alternate strategies and recommending environmental modifications with the aim of helping him or her to achieve a specific behavioral goal ${ }^{10}$. The goal oriented strategy consists of assisting the patient to engage in specific behavioral activity such as reading the newspaper. Attitude oriented rehabilitation involves helping the patient to adjust psychologically to the limitations imposed by the impairments ${ }^{10}$. This involves counseling the patient to surrender unrealistic goals, learn to accept the current situation and face the challenges imposed by the visual impairment.

Vision rehabilitation requires a holistic consideration of the persons needs rather than concentration on his/her visual needs. Low vision patients therefore, should be seen as a whole person having ranges of physical and psychological needs ${ }^{15}$. Rehabilitation programs rely on interdisciplinary teams of professionals to provide effective service. This type of approach provides comprehensive services to the partially sighted. The social and economic requirements of the patient need to be given attention. This implies that, apart from the visual needs of the patient which can be addressed by the optometrists and ophthalmologists, factors such as the social, psychological and economic status need to be adequately addressed by other professionals. In caring for the low vision patient, therefore, the optometrist finds himself or herself as a part of a rehabilitation group concerned with the patient's functioning to his or her full potential. Other than the optometrist, the professionals from whom the low vision patient can benefit include: Ophthalmologist, Psychologist, Psychiatrist, Orientation and mobility instructor, Visual therapist, Social worker, Reading specialist, Special educator Occupational therapist et cetera. A comprehensive health care environment therefore best suits visual rehabilitation.

As medical, surgical and/or routine optometric services cannot improve the vision, the only optometric option left for low vision patients for vision improvement and independent functioning is via magnification, minification, illumination control and/ or environmental modifications et cetera. In many countries including South Africa, this is the domain of the optometrist. Quite often, the optometrist may be the first contact that a low vision patient has with any rehabilitative professional. The optometrist is therefore, involved in the initial eye examination of the low vision patient and the diagnosis of the etiology and degree of visual disability. Depending on the clinical findings, the optometrist may refer the patient to the ophthalmologist for further evaluation and appropriate treatment. When considered necessary, the patient may be referred to other professionals such as the clinical Psychologists, Social workers et cetera. In certain cases, referral should take place before the optometric treatment is commenced. This is because the assessment, treatment and rehabilitation results of one of these professionals may influence or facilitate the optometric component. For instance, referral to the ophthalmologist for active disease management should be done before optometric services. If there are indications that the patient is exhibiting certain serious psychological factors as a result of the vision loss, he/she may need to be referred for psychological management before optometric service is commenced.

\section{Low vision care in South Africa}

In South Africa, low vision services are provided by optometrists, and there are a limited number of these who engage in low vision care ${ }^{4}$. The smaller number of patients and the prohibitive expensive nature of low vision aids have limited the financial viability of low vision services in South Africa. As a result, 
very few optometrists venture into this field despite their extensive training ${ }^{16}$. Consequently, much of the burden of the low vision services is carried by non-governmental organizations (NGOs) and the South African National Council for the blind $(\mathrm{SANCB})^{16}$. Low vision clinics are available at the optometric teaching institutions namely, University of Limpopo, University of Johannesburg, University of KwaZulu Natal and University of Free State. In addition, Optima College in Pretoria manages low vision clinic with optometric services provided by students and staff at the University of Johannesburg ${ }^{4}$. In South Africa, there are an estimated 10 optometrists offering full low vision services in private practice and although optometric services have been introduced into a few government hospitals, such services do not include specialty areas such as low vision yet, although the National Department of Health has plans to change the situation ${ }^{4}$.

It has been recommended that a low vision clinic should be established at primary and/or secondary health levels as part of the services provided by the optometrist and that patients with low vision should be referred to these low vision clinics for appropriate assessment and effective management ${ }^{16}$. Efforts are being made to introduce low vision care into Government hospitals in South Africa. For example, there are indications that the Limpopo Province Department of Health is to establish a low vision unit at Elim hospital. There is therefore, a need for information to facilitate the process of introducing low vision care into government hospitals. Such information will be useful to the optometrists, the low vision practitioner and the hospital managers.

\section{Introducing low vision care into Government health care services}

Government health care units in South Africa are in the form of districts. These constitute the intermediate level administrative health care units. A large proportion of health care services are provided by these health care units. Eye care facilities are available in nearly all the major government hospitals, providing ophthalmological services only or with optometric services. There are indications that the future plans of the National Department of Health for prevention of blindness will include low vision care services $^{16}$. This article therefore, discusses issues relating to introducing low vision care into public eye care services. The discussion includes issues such as defining the population in need of low vision care, human resources, infrastructure, equipment and low vision devices. To put the resources needed into context, the assessment procedures involved in low vision care are briefly discussed. This assessment aspect of the discussion will be useful to the low vision practitioner.

\section{Defining the population for the low vision care}

It has been recommended that eye care be planned for a unit population such as a district, and to consider population density, geographic coverage and accessibility when planning eye services at a district level $^{12}$. Subsequently, it will be necessary to calculate the need for services such as low vision care. The need for low vision services in a district can be calculated using data from population-based studies such as prevalence of low vision and blindness surveys. Although, the majority of patients in such surveys would be those with treatable causes such as refractive errors and cataracts; there will be those with incurable eye conditions with some residual vision which can be effectively utilized with low vision devices ${ }^{12}$. Depending on the cataract surgical rate and coverage of refractive services, it has been estimated that approximately 20$25 \%$ of the number of visually impaired people may benefit from low vision services ${ }^{17}$. Combining this estimate with the low vision prevalence data that are available in a Province, the low vision care need can be estimated.

\section{Human resources}

In planning health care services, the human resources needed should be given due attention. In case of low vision clinics, at least one low vision care practitioner will be needed in each hospital that operates such a clinic. This may be one of the optometrists in the hospital who has special interest in low vision care or an eye care practitioner with a post-qualification training in low vision care or an optometrist who has been involved in low vision care since graduation. A newly graduated optometrist or one who graduated within the past two years but had keen interest in low vision care at the University may have enough knowledge to handle low vision cases. Those who had graduated more than two years ago and have not been involved in 
any form of low vision care would need a refresher course to be able to manage low vision care cases effectively. This may be arranged with any of the optometry training institutions or with a low vision care practitioner. If possible, assistance of a low vision lecturer or a low vision practitioner should be sought to work for a few days with an optometrist who will be managing the low vision clinic in the government hospital.

\section{Infrastructure}

Physical space is another important issue for consideration. It is advisable that a separate room be allocated for low vision care. All the low vision testing equipment and trial low vision devices will be kept in that room. The room must be large enough to avoid patients bumping into equipment. Also, in most cases, low vision patients come with somebody (spouse, parent or friend) who may need to sit in the testing room during the examination. Preferably, the room should have dimmer switch/es to vary the room illumination. This is necessary because the illumination required by low vision patients vary. While some would prefer bright illumination, others may prefer normal room level or dim illumination. This preference may be related to factors such as the etiology of the low vision or personal preference of the patient. During the testing procedure, illumination preference has to be established. When requesting for a large space for the low vision clinic room, the special status of low vision patients should be explained to the decision makers of the hospital in order to justify the need. Even when one of the optometrists who engage in general practice is responsible for low vision on specific day/s, it is recommended that a separate clinic room be allocated for low vision care.

\section{Equipment}

Resource allocation for equipment is an important issue in introducing low vision care into hospitals. Mc Veigh ${ }^{18}$ has highlighted what can be done to maximize success in obtaining equipment for a clinic: There is a need to assess the situation and define the mission. What type of patient will be examined? How many patients will be examined? What type of services will be provided? After this assessment, there is a need to make an inventory of existing equipment and their maintenance record. The equipment shortfall could then be identified and request for purchase submitted. There may be a need to educate the decision makers by providing technical data and coloured brochures ${ }^{18}$. Basic optometric equipment used for testing normally sighted patients such as those for refraction, external and internal examination, visual field, colour vision, contrast sensitivity testing et cetera are needed for basic examination of the low vision patients and should be purchased for the low vision clinic. For refraction, trial lenses and frames are recommended rather than the phoropter. The latter tends to obstruct patients who would probably adopt an abnormal head posture. Such patients would include those with a central scotoma who prefer to adopt an eccentric view for testing acuity ${ }^{19}$. Phoropters also have the disadvantage of reducing the light level that may influence a person's visual capacity ${ }^{19}$. Major equipment such as autorefractor, visual field analyzers et cetera may be shared with other clinics.

Visual acuity measurement is a major aspect of low vision assessment as the prescriptions for the patient are often based on the VA values. Specially designed low vision distant VA chart (able to measure up to visual acuity 6/200) such as the Feinbloom chart should be available. Preferably numeral or illiterate charts should be available for use with the illiterate patients and children who are not able to read alphabets or numerals. The Bailey and Lovie distance VA char ${ }^{20}$ or any of its derivatives such as Oduntan and Briggs $\operatorname{logMAR}$ charts $^{21}$ are also useful. There are many types of near VA charts. Preferably, near charts for low vision should include letters, words and paragraph reading types. A popular chart is the Lighthouse near acuity test chart. This chart is presented in $\mathrm{M}$ (meter), $40 \mathrm{~cm}$ acuity notation and distance acuity equivalent. It also contains the power needed to read an average print of $1 \mathrm{M}, \mathrm{J} 5$ or 8 point. Other near vision charts include Keeler A series, MNREAD and the Bailey logMAR word reading chart. The practitioner is, however, encouraged to stick to one or two types. For children, number based charts such as the Lear Number chart or picture-based charts such as the Kay picture test chart are useful. Children oriented testing devices such as picture materials for visual acuity should be available. Thick line papers and crayons should be available as well for children assessment. There should be a wide range of optical, electronic and 
illumination control devices for assessment and training of the patient (see Table 1). The optical devices may even be loaned to the patient on short term basis.

Table 1: Categories of equipment needed for a low vision clinic. There are several design types and shapes of these devices, for instance, there are many design types of hand magnifiers. Also, hand magnifiers can be illuminated or non-illuminated. Telescopes can be monocular or binocular and each of these can be focusable or non-focusable.

\begin{tabular}{|l|l|}
\hline Optical & Non optical \\
\hline Magnifiers and minifiers & Electronic devices \\
Spectacle (microscopes, & Closed circuit televisions (CCTV), \\
binoculars, half eye and full eye) & Video magnifiers (Hand held or \\
Hand and Standing (Illuminated, & with panel). \\
non illuminated). & Electronic software (Zoomtext, Jaws, \\
Minifier. & Supernova, dolphin pen). \\
\hline Telescopes & Illumination controls \\
Distance, near (fixed focus, & Sunshades (with and without side \\
focusable, monocular, & Shield). \\
binoculars, autofocus, bioptic). & Typoscopes \\
& Pinholes (single and multiples). \\
\hline
\end{tabular}

Different types of computer software for the visually impaired such as JAWS, Zoom text et cetera and a computer should be purchased. In addition to being used to examine the patient, these different types of low vision devices are needed in the low vision clinic for demonstration to the patients. In addition to the optical, electronic and illumination control devices listed above, there are gadgets needed for daily living activities which are needed in the clinic for demonstration to patients. These include needle threader, money dispensers, large print bible, cross words, talking watches and clocks, talking calculators, large index playing cards, bold and wide line papers, and felt tipped pens.

Table 2: Major companies supplying low vision devices in South Africa, their contact details and the items that they supply.

\begin{tabular}{|l|l|l|}
\hline Company & Contact details & Items supplied \\
\hline Danker lenses & $\begin{array}{l}\text { Phone: (011) 884 0346 } \\
\text { Cell: 083 266 7363 } \\
\text { Fax: (011) 883 9272. } \\
\text { danker@iafrica.com } \\
\text { www.opticalsupplies.co.za }\end{array}$ & $\begin{array}{l}\text { Low vision acuity charts, optical devices (telescopes } \\
\text { and magnifiers) } \\
\text { non-optical and electronic devices. }\end{array}$ \\
\hline $\begin{array}{l}\text { Neville Clarence } \\
\text { Technologies (NCTec) }\end{array}$ & $\begin{array}{l}\text { Phone: (012) 452 0389 } \\
\text { Fax: (012) 452 0385 } \\
\text { www.nctec.co.za } \\
\text { accounts@nctec.co.za }\end{array}$ & $\begin{array}{l}\text { Optical (telescopes and magnifiers) } \\
\text { and electronic devices including } \\
\text { Software } \text { et cetera. }\end{array}$ \\
\hline $\begin{array}{l}\text { South African National } \\
\text { Council for the blind } \\
\text { (SANCB) }\end{array}$ & $\begin{array}{l}\text { Phone: (012) 452 3811 } \\
\text { Fax:012 346 8751 } \\
\text { Arlene@sancb.org.za } \\
\text { www.sancb.org.za }\end{array}$ & $\begin{array}{l}\text { Electronic devices (Closed circuit } \\
\text { Television, video magnifiers), } \\
\text { optical devices (telescopes and magnifiers), non- } \\
\text { optical devices } \text { et cetera. }\end{array}$ \\
\hline Medical distributors & $\begin{array}{l}\text { Phone: (011) 2032121 } \\
\text { Fax: (011) 314 3016 }\end{array}$ & $\begin{array}{l}\text { Optical devices. } \\
\text { (Keeler products) }\end{array}$ \\
\hline ICEE South Africa & $\begin{array}{l}\text { Phone: 031 202 3811 } \\
\text { Fax: 031 202 3835 } \\
\text { khotso@iceeafrica.co.za } \\
\text { www.icee.org }\end{array}$ & $\begin{array}{l}\text { Optical, non-optical devices and } \\
\text { electronic devices. }\end{array}$ \\
\hline Sensory Solutions & $\begin{array}{l}\text { Phone: 012 664 7704 } \\
\text { Fax: 012 664 7706 } \\
\text { info@sensorysolution.co.za } \\
\text { www.sensorysolutions.co.za }\end{array}$ & $\begin{array}{l}\text { Electronic devices } \\
\text { (hardware and software) }\end{array}$ \\
\hline
\end{tabular}


These various devices can be obtained locally in South Africa. The contact details of the suppliers and the devices that are supplied by each are shown in Table 2. Electronic devices are expensive, but are quite valuable where high levels of magnification are needed as they provide greater magnification with less aberration than optical devices. Also, they are quite useful in work environments such as in schools (regular or special). They are particularly useful to the elderly patients for leisure reading such as reading their letters or religious books such as the bible. Technology of the electronic devices is constantly changing and improving, it is important to purchase a new model so that maintenance and /or requisition of spare parts may not be a problem. It is therefore, important that suppliers are informed that the latest version of any electronic device is needed. It is important to note that low vision care is supplementary to ophthalmological and optometric care. Patients are typically referred to the low vision clinic by practitioners in those departments. Therefore, low vision care should not be introduced into a hospital or clinic as an independent unit.

\section{Assessment of visually impaired patients}

\section{Diagnosis and classification of the visual impairment}

Diagnosis and documentation of visual impairment is the most important aspect of the low vision examination. It sets the ground work for the treatment plan which may include the prescription of spectacles, optical, non optical, and / or electronic devices; and / or program of vision rehabilitation ${ }^{22}$. Those with low vision will need to be examined further and be provided with low vision devices. Those who are considered to be blind can be recommended for the use of Braille, Braille printer and typewriter. This category of patients may also need referral for orientation and mobility, social and/ or psychological needs. Also, environmental modification needs may be considered. The low vision patient will need assessment for appropriate devices and illumination control.

\section{Assessment of low vision patients}

This section is included in this article in order to justify the various devices that may be required for the low vision clinic and to refresh the memory of the low vision practitioner who might have graduated a few years back and is now appointed to run the low vision clinic. Examination of a low vision patient is a functional assessment to determine if the remaining vision or visual field can be improved to enable the patient to perform the specific task or tasks that he or she wishes to perform. Appointment system, where a patient is booked for a particular day and hour is recommended. A patient who is scheduled for a low vision examination should be advised to bring any previous or current spectacles and other optical devices that he or she may have. This will help the practitioner to know what visual aids are currently available to the patient and how and why they need to be upgraded, if required. Any document relating to previous medical treatment or eye examination, if available, should be brought on the day of examination. This will provide some information about the general and eye health of the patient. Those who may not be able to provide necessary information during examination such as children or those with other disabilities should be advised to come with a family member or friend. The possible duration of the examination should be communicated to the patient during appointment booking.

Generally, the procedure is similar to that of the normally sighted patient but there are certain specific differences due to low level of vision and the psychological issues involved in low vision care. The procedure commonly used in the assessment of low vision patients include general observation, case history, external examination, disease diagnosis, visual acuity, refraction, visual field, contrast sensitivity and color vision tests. All these procedures may not be applicable to every patient, and the sequence may vary significantly. The tests chosen depend on the conditions being examined and the specific needs of the patient. For comprehensive care for these patients, optometrists must understand and perform appropriate visual examination and prescribe relevant optical and adaptive technologies necessary for goal oriented vision rehabilitation. In some cases, the low vision practitioner provides the needed vision rehabilitation. In others, he or she may need to refer the patient for occupational therapy with regard to low vision rehabilitation. 
The basic examination includes the following:

\section{General observation}

At the first visit of a low vision patient, there is a need to observe the patient as he or she enters the consulting room. This enables the examiner to evaluate the patient in terms of the degree of visual disability, and possible contributory factors for the impairment. Observations should include mobility, visual status and physical disability of the patient. These observations may influence the type of devices to be prescribed for the patient.

\section{Case history}

The case history is an important aspect of low vision evaluation and should be as comprehensive as possible. The case history for a low vision patient differs from that of a normally sighted person because issues relating to social, economic and psychological factors with regard to the patient's daily living activities are often part of the case history. For preschool children, the parents or guardians are obviously the preferred source of case history. For older children, contribution of the parents or guardians to the information provided by the child can be very useful. Generally the major areas of interest that the practitioner should try to establish are: the main concern of the patient in terms of his or her vision, the main assistance that the patient expects from the practitioner and the cause and duration of the visual problem. Generally the case history proceeds as follows: the chief complaint, ocular, visual and systemic history, family visual and medical history, visual capability, mobility, educational history, vocation, avocation, optical and non-optical devices currently being used and illumination preference. Particularly, the specific goal/s (the want and need) of the patient should be established. For effective outcome of the low vision care, the goal of the patient should be limited and realistic relative to the residual vision of the patient. Where the goal/s of the patient is/ are not realistic, he or she must be informed appropriately and advised of the achievable goals.

\section{External and internal eye examination}

With penlight, ophthalmoscope and or slit lamp, the external and internal eye examination should be done to establish the ocular disorder resulting in visual impairment. Also, whether or not the disorder is active should be established at this stage. If the eye disease is still active, patient should be referred to an ophthalmologist for further evaluation and management.

\section{Visual acuity tests (distance and near)}

Visual acuity should be measured monocularly and binocularly, preferably with current spectacles first, if available. Binocular VA should preferably be measured first, then the eye with better vision and lastly the eye with poorer vision. This sequence reduces frustration and encourages the patient. The VA should be measured at 10 feet or 3 meters or shorter distances $(1.5 \mathrm{~m}$ or $1 \mathrm{~m})$ if necessary. These closer distances affords a more accurate VA measurement and help psychologically to maximize the ability of the patient. Subsequently, the VA values should be converted to 6 meters equivalent. Eccentric viewing and guessing should be allowed when necessary.

\section{Refraction}

Where possible, retinoscopy should be done accurately. The retinoscopy or other objective refraction values or powers of a previous spectacle are often used as the starting point for subjective refraction. Where indicated, radical retinoscopy, in which shorter distance and off-axis scoping is done, should be used ${ }^{23}$. Subjective refraction is a very important component of low vision assessment, as in certain instances, the objective tests may not be reliable due to conditions such as cloudy media. The refraction procedures have been described effectively by Sacharowitz ${ }^{24}$. The distance VA should be accurately corrected before the near refraction is embarked upon. In most cases, the subjective refraction values are used as refractive values in the calculation of the magnifying powers. 


\section{Visual fields}

Both the central and peripheral visual fields should be examined. In a variety of clinical situations, static perimetry have been found to be superior to kinetic types for low vision cases such as age-related macular degeneration $^{25,26}$. Tangent screen and Amsler grid are useful devices for central visual field evaluation. Amsler grid is very useful in cases of compromised macular integrity as it is able to reveal slight defects in some pre-age-related macular degeneration patients ${ }^{27}$. The visual field taken for children can be helpful in advising the parents on mobility and posture related issues ${ }^{28}$. It has been suggested that Goldman and Humphreys visual field analyzers can be performed binocularly for children ${ }^{29}$. The procedure for visual field measurement is similar to that of normally sighted patients.

\section{Colour vision}

Many conditions of the visual system that affect the macular area such as macular degeneration, diabetic retinopathy and optic atrophy may be associated with colour perception abnormality. Colour deficiency may be an indication of cone dysfunction, therefore may be associated with poor VA. For instance, typical rod (monochromats) achromats have no functioning cone receptors; hence have poor VA of $6 / 36$ to $6 / 60 .{ }^{30}$ Appropriate colour discrimination test/s should be used. Ishihara pseudoisochromatic plates cannot be used to test for blue-yellow (tritan) deficiencies; therefore they cannot be used for cases such as age-related macular degeneration where blue-yellow colour deficiency is involved ${ }^{24}$. For adults, a simple test that can be administered and scored quickly is the Farnsworth Panel D-15 saturated or unsaturated. Also, it can be used for evaluation of the children because it has large target sizes and can be used in a matching format for preschool children $^{31}$. It is, however, not useful for preschool children; for these, a form of colour matching test such as Hyvarinen's Quantitative colour vision test can be used to obtain some information about their colour vision status ${ }^{31}$. For each test, the procedure is the same for the normally sighted.

\section{Contrast sensitivity}

It may be necessary to include contrast sensitivity (CS) measurement in the evaluation of a low vision patient. This is because CS may be reduced in certain low vision patients, especially those with diabetic retinopathy and macular degeneration. The Vistech and the Pelli-Robson charts can be used for contrast sensitivity testing. For children, picture based tests such as the Hiding-Heidi or Mr. Happy tests can be used. A number of investigators have established that CS measured at a low to mid-spatial frequencies is a useful predictor for reading rates in partially sighted patients ${ }^{32-34}$.

The basic examination of the patient is followed by calculation of appropriate powers of magnifiers or telescope, establishment of illumination control devices and training the patient in the use of the device/s. The type of device needed, whether optical, non optical, illumination control or a combination of these would be decided. Also, where necessary, it needs to be decided whether the device/s will be monocular or binocular. For example, a telescope or magnifier may need to be monocular or binocular depending on the similarity or differences in VA between the two eyes. When the VA difference is one lines or less, binocularity should be assessed and decision taken on monocular or binocular device. When the difference is greater than one line, monocular device should preferably be considered, except where there are indications suggesting otherwise. For those who need optical devices in the form of magnifiers for near or telescopes for far or near, the powers of the device/s should be calculated. Contrary to the few methods for calculation of power for telescopes, there are many methods for calculation of the magnifier power. This will depend on the type of chart being used to measure near visual or reading acuity for the patient. A few of the methods for power calculation are described below.

\section{Calculation of magnifying power for distance}

A commonly used method for calculating the magnification power or working (reduced) distance needed by a low vision patient is the ratio of the current best corrected VA and the desired (goal) VA of the patient. The practitioner should be able to estimate the VA that will be needed (goal or desired VA) for a particular task. For most daily distance activity, 6/12 (20/40) are considered to be the goal VA. Example: A patient has current corrected VA of $10 / 60(3 / 18)$ at 10 feet (3 meters). This is equivalent to 20/120 or $6 / 36$ 
respectively at 6 meters. If it is estimated that the patient will achieve his or her reading goal if he or she can read 20/40 or 6/12, the estimated power of the device needed will be: $120 / 40=3 X$. The telescope of the same power should then be tried on the patient and refined using other powers subjectively to establish the power acceptable to the patient.

\section{Calculation of magnifying power for near}

Best corrected near VA values are usually employed to calculate the estimated power of magnifier required by the patient to read at near. The ratio of current near VA and desired or goal VA is used to predict the magnification or working distance required by the patient. Different near charts require different ways of calculating the power. In addition, there are a few charts such as the Lighthouse and Precision Vision near charts which have pre-determined power needed to read an average print of 1M (J5) (8 point) indicated on the chart.

Example 1. Using the Lighthouse or Precision Vision near chart, if a patient can read 5M and he wishes to read $1 \mathrm{M}$, he or she would need a $+12.00 \mathrm{D}$ lens as indicated on the charts. For this chart, near vision is tested at $40 \mathrm{~cm}$ with best distance correction and if accommodation is insufficient, a $+2.50 \mathrm{D}$ add will be provided for reading.

Example 2. For calculation of magnification powers using near acuity charts which do not have powers indicated, a simple method will be to use the ratio of the best VA (current VA) and the required VA (Goal VA). This method is also applicable when the Lighthouse and Precision Vision charts are used at distances other than 40 centimeters.

\section{Magnification $=$ Visual acuity achieved \\ Required visual acuity}

For instance, if a patient is able to read 10/100 (20/200) (6/60) at $25 \mathrm{~cm}$ and wishes to read print which is equivalent to $20 / 80(6 / 24)$ at the same distance, the magnification required equals $60 / 24$ or $200 / 80=2.5 \mathrm{x}$. This is equivalent to $+10.00 \mathrm{D}$ lens or reduction of working distance to 10 centimeters.

Example 3. Another method of calculating the magnification required by a patient at near is the Kestenbaum's method ${ }^{35}$. This is based on the dioptres of add needed to read $1 \mathrm{M}$ print and is approximately equal to the reciprocal of the distance acuity. The reciprocal of the distance VA is taken as the predicted value of the magnifier required to read $1 \mathrm{M}$ at near. Example: If a patient can read 6/120 at 6 meters, the near addition required is considered to be $120 / 6$ which is equal to $+20.00 \mathrm{D}$. This procedure is not accurate but may provide a basis for subjective determination of the power of magnification that a patient will need to read N8 print.

Method 4: Determination based on current add and magnification required for goal VA. Example: A patient can read $4 \mathrm{M}$ print at $40 \mathrm{~cm}$ with an add of $+2.50 \mathrm{D}$. What add will he or she require to read $1 \mathrm{M}$ print? It should be noted that $4 \mathrm{M}$ print is 4 times as large as $1.0 \mathrm{M}$ therefore, the magnification required will be 4 times. The power of magnification required will be $4 \mathrm{x}+2.5 \mathrm{D}=+10.00 \mathrm{D}$. The magnification required is approximately $2.5 \mathrm{x}$.

Method 5: The use of LogMAR method for determining the magnification, power or reduction in working distance required by a low vision patient is a relatively new method. This method involves the use of a $\log$ MAR near chart. The calculation is based on the ratio of current VA and the goal VA of the patient based on the $\operatorname{logMAR}$ ratio of $1.2589(10 \sqrt{10})$ or $0.1 \log$ unit. Example: A patient can read 30 point print at $25 \mathrm{~cm}$, but his goal is to read 12 point. The ratio between these two reading acuity values is 4 . This is obtained by calculating how many times that 30 can be divided by 1.2589 to arrive at 12 . This implies that the magnification required is $4 \mathrm{x}$. This magnification can be achieved by increasing the dioptric power of 25 $\mathrm{cm}$ four times. The dioptric power of $25 \mathrm{~cm}$ is $4.00 \mathrm{D}$ therefore, the power needed to provide $4 \mathrm{x}$ magnification is $4 \times 4=+16.00 \mathrm{D}$. Also, the $4 \mathrm{x}$ magnification can be achieved by reducing the working 
distance to a quarter of the original value. A fourth of $25 \mathrm{~cm}$ is $6.25 \mathrm{~cm}$. The dioptric power of $6.25 \mathrm{D}$ is $+16.00 \mathrm{D}$. This power can be in the form of accommodation or a magnifier. Details of this method have been described in my previous article ${ }^{36}$.

The discussions above show that there are many different types of near VA or reading charts that may be used for VA and reading acuity measurements in order to estimate magnifier powers for low vision patients. A few of these charts are therefore, necessary in the low vision clinic. The practitioner would decide which one he or she prefers to use regularly and which one to alternate when the situation arises. Following the calculations at far or near, the power obtained should be subjectively refined to obtain the power that the patient prefers. There are a few factors that may result in poor performance on the reading goal. This may be due to one of the following: indication of need for more magnification; need for eccentric viewing; resistance to close working distance or simply difficulty with the reading task as in case of a patient who has not read for ten years ${ }^{37}$. It is necessary to try various levels of illumination that best suits each patient. High, medium and low level of illumination should be tried to establish which level that the patient prefers. Illumination control can result in a significant improvement in some patients. With changes in illumination, the power of the magnifier may be adjusted if necessary.

\section{Patient education and management options}

Following the determination of the appropriate power/s of device/s for the patient and determination of appropriate illumination level for reading, the patient should then be educated on the advantages and disadvantages and costs of the various devices. An appropriate device will have to be selected for the patient based factors such as his or her age, physical status, preference, similarity or differences in VA in both eyes, ability to use the device effectively et cetera. Management options will include the use of reduced working distances, prescription of optical and or non-optical devices and or use of eccentric fixation. Simple, cheaper and easy-to-use option is given preference over costly and complex devices. For example, if a patient who needs to watch television needs $2 \mathrm{x}$ telescope, it will be cheaper and easier for him or her to half the distance at which he or she watches television to achieve the same goal. Whatever device/s selected for the patient should be tried on him or her with the illumination established earlier to ensure that the vision is still the same or better with the selected device/s.

\section{Patient training in the use of devices and follow-up}

The patient should be trained to use the device/s effectively in terms of working distance, posture and ergonomics, handling of the device, and how to take care of the devices. A device should not be prescribed for the patient until it is certain that he or she can use it effectively. Poor knowledge of use of a device can lead to rejection. A follow-up of the patient is a necessity. The patient should be requested to come back for a follow-up after one or two weeks. At that time, it will be necessary to ascertain how he or she is adjusting to the use of the device/s and to establish if he/or she has any problems with the use and care of the device/s. When the patient comes for follow-up, he or she should be asked to demonstrate the use of the device and to comment on his or her vision with the device/s. Such comments will dictate the need for continued use of the device or the need for an amendment.

\section{Conclusion}

Optometrists, optometry managers and clinical managers in government hospitals need certain information that will enable them introduce low vision services into public health care services. The information provided here are by no means all that are needed. Further information can be obtained from low vision textbooks, low vision journal articles, low vision manuals and low vision websites on the internet. Although, this article was written with South Africa in mind, the content will be useful in other countries where there is a need to introduce low vision care services into exiting comprehensive health care services. 


\section{References}

1. Haffner AN. Public health value of optometry in a comprehensive health care environment. Optom Vis Sci 1996 73 299-300.

2. Walls LL. Issues for optometrists relating to inter-professional relations in a hospital and medical center. Optom Vis Sci 199673 307-308.

3. Oduntan AO, Nthangeni M, Ramudzuli MR and Madu S. Causes and prevalence of low vision and blindness in black South African adults in the Limpopo Province. S Afr Optom 2002 62 8-15.

4. Sacharowitz HS. Visual impairment in South Africa: achievements and challenges. S Afr Optom 200564 139149.

5. International statistical classification of diseases and related health problems $10^{\text {th }}$ revision. Vol. 1 Diseases Tabular List. World Health Organization (WHO), 1992.

6. World Health Organization (WHO). Management of low vision in children. Program for the prevention of blindness, Bangkok, 1992; WHO/PBL/93.27.

7. The invitational workshop. Towards a reduction in the global impact on low vision. The International Society for Low Vision Research and Rehabilitation, New York NY USA 2005.

8. World Health Organization (WHO). Magnitude and causes of visual impairment. Fact sheet No. 282 November, 2004.

9. Pougnet VN. Report of the Working Group to the National Eye Care Committee on Eyecare Program for South Africa, 1995.

10. Massof RW. A systems model for low vision rehabilitation. I. Basic concepts. Optom Vis Sci 1995 72 725-736.

11. Kupfer C. The low vision education program: Improving quality of life. Optom Vis Sci 1999 76 729-730.

12. World Health Organization (WHO). Prevention of blindness programme. Global initiative for the elimination of avoidable blindness: Vision 2020 The right to sight. Geneva, Switzerland: WHO press release WHO/12, February, 1999.

13. Minto H, Awan H. establishing low vision services at secondary level. Community Eye Health 2004175.

14. Emener WG, Hollingsworth DK. (Eds). Critical issues in rehabilitational counseling. Springfield. IL: Charles C Thomas. 1984.

15. Bairstow M. Low vision; Social and rehabilitation needs. Optician. 1998216 18-21.

16. Department of Heath, Directorate of chronic diseases, disabilities and geriatrics. National guideline for prevention of blindness in South Africa (2002).

17. Asia Pacific Low Vision Workshop. Report of a workshop. Hong Kong 28-30 May, 2001.

18. Mc Veigh F and Bifaret L. Criteria and issues of space and equipment allocation and utilization in a comprehensive health care environment. Optom Vis Sci 199673 344-349.

19. Mcnaughton J. Low vision assessment. Eye essential series. London: Elsevier Butterworth-Heinemann. 2005 p44.

20. Bailey IL, Lovie JE. New design principle for acuity letter chart. Am J Optom Physiol Opt 1976 53 740-745.

21. Oduntan AO and Briggs ST. An Arabic letter distance visual acuity chart for young children and illiterate adults. Ophthal Physiol Opt 199919 431-437.

22. Gormenzano SR. The examination and vision rehabilitation treatment of the individual with vision impairment. Optom $200576399-404$.

23. Mehr BE, Freid AN. Low Vision Care, Professional Press. USA, Chicago, 1975 p84.

24. Sacharowitz HS. Review of management of age-related macular degeneration (ARMD) in the optometric practice. S Afr Optom 19985766 -72.

25. Fortney GL, Krohn MA. The limitations of kinetic perimetry in early scotoma detection. Ophthalmol $1978 \mathbf{8 5}$ 287-293.

26. Yellen $M$ and Sharman J. Static versus dynamic visual field evaluation, with emphasis on the utility of the Friedman visual field analyzer. J Am Optom Assoc 1979 50 95-99.

27. Swan PG, Lovie-Kitchin JE. Age related maculopathy. II: the nature of the central visual field loss. Ophthal Physiol Opt 199111 59-70.

28. Bevan JD. The optometric management of a child with low vision. Aust J Optom 198366 142-146.

29. Brower J. A practical guide to low vision assessment and dispensing. Optom Today 2001 Feb 9, 34-36.

30. Birch J. Colour deficiency: An Introduction. Optician 1999218 22-25.

31. Jackson AJ and Saunders KJ. The optometric assessment of the visually impaired infant and young child. Ophthal Physiol Opt 199919 S49-S62. 
32. Brown B. Reading performance in low vision patients: relation to contrast and contrast sensitivity. Am J Optom Physiol Opt 19818 218-226.

33. Rubin GS and Legge GE. Phychophysics of reading VI - The role of contrast in low vision. Vision Res. 198929 89-91.

34. Leat SJ and woodhouse JM. Reading performance with low vision aids: relationship with contrast sensitivity. Ophthal Physiol Opt 199313 9-16.

35. Kestenbaums A, Sturman RM. Reading glasses for patients with poor vision. Arch Ophthalmol 195656 451-470.

36. Oduntan AO. A practical near reference table for low vision practitioners: Design and applications. S Afr Optom 200665 157-162.

37. Sacharowitz HA. Low vision workshop. Vision Africa, Johannesburg, 1999. 